\title{
Investigation of Scavenging, Combustion and Knock in a Two-Stroke SI Engine Operated with Gasoline and CNG
}

\author{
Fontanesi S., Severi E. ${ }^{1)}$ Bozza F., Gimelli A. ${ }^{2)}$ \\ 1) University of Modena and Reggio Emilia, Department of Engineering "Enzo Ferrari”" \\ Strada Vignolese 905, 41125 Modena, Italy (E-mail: stefano.fontanesi@ unimore.it) \\ 2) University of Naples Federico II, Department of Mechanical Engineering \\ Via Claudio 21, 80125, Napoli, Italy (E-mail: fabio.bozza@unina.it)
}

Received on April 20, 2012

\begin{abstract}
The paper reports a combined experimental and numerical investigation of a small unit displacement two-stroke SI engine operated with either Gasoline and Natural Gas (CNG).

It is widely recognized that for two-stroke, crankcase scavenged, carbureted engines the scavenging patterns (fuel short-circuiting, residual gas distribution, point wise lambda field, etc.) plays a fundamental role on both engine performance and tailpipe emissions. To properly characterize the engine behavior in terms of scavenging patterns and combustion, a detailed multi-cycle 3D-CFD analysis of the scavenging process is at first performed starting from preliminary $1 \mathrm{D}$ computed boundary conditions provided by a in-house developed 1D model of the whole engine.
\end{abstract}

In order to assess the accuracy of the adopted numerical approach, comparisons between numerical forecasts and experimental measurements of the instantaneous in-cylinder pressure history for steady-state operations of the engine are at first performed and shown in the paper. Subsequently, the activity is focused on the investigation of knock occurrence. In order to limit the computational cost of the simulations, calculations are at first carried out within the 1D modeling framework, where customized quasi-dimensional combustion and knock models are used. In particular, the 1D model is used to compute a numerical knock index which can be useful to address the tuning of the spark advance, given a prescribed and controlled percentage of knock released heat. At the end of the simulation process, the 1D knock index is qualitatively compared to results obtained from full 3D knocking analyses for different incylinder compositions and spark timings. The intrinsic knock-resistance of the CNG fuel is finally numerically exploited, through variations of both compression ratio and spark advance.

\section{KEY WORDS:（Standardized） Heat • Engine, 2-Stroke Engine, CNG, Gasoline, Scavenging,}

\section{Combustion, Knock [A1]}

\section{Introduction}

In recent years, due to the constantly increasing oil demand and consciousness of limited oil reserves, automotive companies and researchers are investing huge resources in new technologies for mass transportation. The main targets are a substantial increase in the fuel conversion efficiency of "conventional-fuelled" engines and the conversion of current production engines to alternative fuels. The latter, in fact, appears to be a credible response to meet target reduction of pollutant engine-out emissions with limited impact on production costs. This is particularly evident when focusing on those vehicles populating a vast portion of urban areas, i.e. three-wheelers, which represent a widespread solution to the mobility problems arising from traffic congestion ${ }^{(1-3)}$. A partial response to the demand of "greener" vehicles could be based on the employment of low-carbon fuels such as natural gas. Thanks to its chemical composition, $\mathrm{CNG}$ can lead to a substantial reduction of the tailpipe emissions, especially if combined with appropriate and innovative engine strategies. In literature a wide variety of contributions dealing with the conversion to $\mathrm{CNG}$ of existing units for automotive applications can be found, but only a few contributions can be found in case of small-size two-stroke engines ${ }^{(4,5)}$. The development of strategies and technologies for this specific engine application can result from investigations through refined numerical procedures involving both $1 \mathrm{D}$ - and 3Dsimulations, capable to model the scavenging and combustion processes, as in ${ }^{(6,7)}$. In particular, 1D tools allow researchers to assess the influence of both operating and design parameters on engine performance with limited computational resources; in addition, they can provide computed pressure and temperature profiles as boundary conditions for the more challenging 3D analyses. The latter are instead necessary whenever local flow patterns and geometrical details play a key-role on the understanding and optimization of the engine behavior.The paper describes an experimental and numerical investigation of a twostroke engine for motorcycle applications based on the synergic use of measurements at the engine test bed, an in-house developed 1D code and a CFD tool for the full-3D multi-cycle analysis of scavenging and combustion. After the model validation phase, the numerical tools are used to investigate the knock limits of the gasoline-fuelled and CNG-fuelled engine, resulting in a preliminary numerical exploration of the potential benefits of the adoption of knock-resistant CNG.

\section{Experimental Measurements}

Experimental investigations are carried out on a traditional singlecylinder, crankcase scavenged, carbureted spark-ignition two stroke engine. Some of the engine technical specifications are shown in Table 1. The engine is installed on a DC test bed and equipped with both instantaneous and overall sensors. Instantaneous pressures inside the crankcase, the cylinder and the exhaust pipe are measured with piezo-quartz-transducers at engine 
speeds ranging from 4000 to $7000 \mathrm{rpm}$, WOT conditions. The outline is shown in Figure 1 below.

Table 1 Engine Specifications

\begin{tabular}{|l|l|}
\hline Engine model & Ported 2-stroke SI \\
\hline Scavenging type & Schnurle \\
\hline Displacement & $50 \mathrm{~cm}^{3}$ \\
\hline Compression ratio & $11.7: 1$ \\
\hline Bore, Stroke & $41,37.4 \mathrm{~mm}$ \\
\hline Max. Power & $4.1 \mathrm{~kW} @ 8000 \mathrm{rpm}$ \\
\hline Max. Torque & $4.7 \mathrm{Nm} @ 7500 \mathrm{rpm}$ \\
\hline Intake port Open/Number/Width & $56^{\circ} \mathrm{BBDC} / 5 / 11 \mathrm{~mm}$ \\
\hline Exhaust port Open/Number/Width & $81^{\circ} \mathrm{BBDC} / 1 / 26 \mathrm{~mm}$ \\
\hline
\end{tabular}

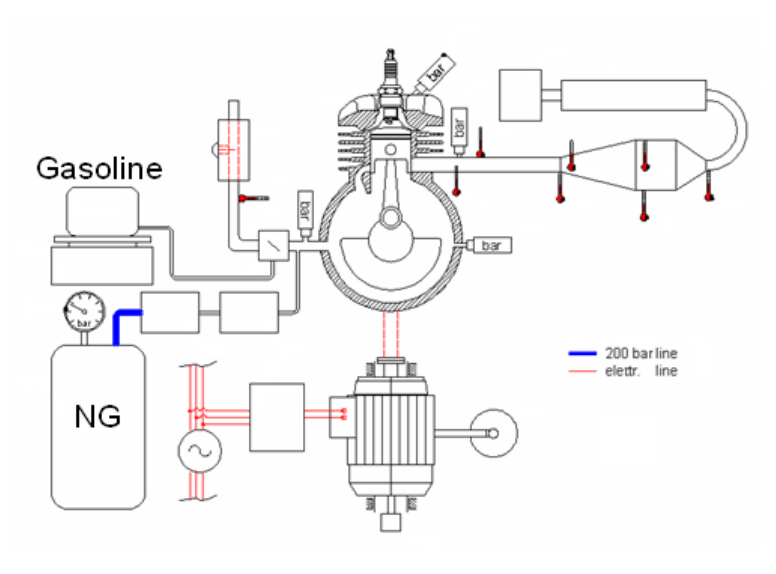

Fig. 1 Experimental test bed scheme

Experimental air mass flow rate, torque, speed, fuel flow rate, gas and wall temperatures along the exhaust system are collected. These last measurements are mandatory to validate the 1Dmodel, especially for the exhaust phenomena. All temperatures were acquired using K-type thermocouples. For NG-operations, the air mass flow rate is measured by a customized hot-film anemometer in view of the reduced air flow rate. The device is calibrated for stationary flows through comparison with a more accurate mass flow rate measurement device.

At each operation point, the engine is fuelled with both commercial gasoline and CNG. The latter is injected in the intake pipe upstream the crankcase, at a moderate over-pressure above the atmospheric one. NG flow rate is adjusted through an electronic control valve, incorporated in the NG mass flow rate meter. NG tests are carried out at the same air index provided by the standard carburetor in the gasoline tests (rich or stoichiometric mixture, $\lambda \cong 0.87-1.0$ ). To ensure the same experimental conditions for the two fuels, the NG tests are performed immediately after the gasoline ones for every condition. During the tests, the air index is at first checked by the hot film anemometer and then adjusted using data from tailpipe emissions. Figure 2a below shows the air mass flow rate for both gasolineand CNG- operations. As expected, the injection of a gaseous fuel at constant air index limits the air flow rate, this resulting in reduced engine permeability. In addition, the lower NG combustion rate leads to an overall relevant reduction in terms of power output, as visible in Figure $2 \mathrm{~b}$ here after. The tested engine does not allow to easily control the spark timing: an advanced spark specification may in fact partially compensate the overall decrease in the power output. Nevertheless, the engine behavior seems satisfactory also for extremely lean NG fuelling conditions, despite the relevant residual fraction typical of this family of twostroke engines.

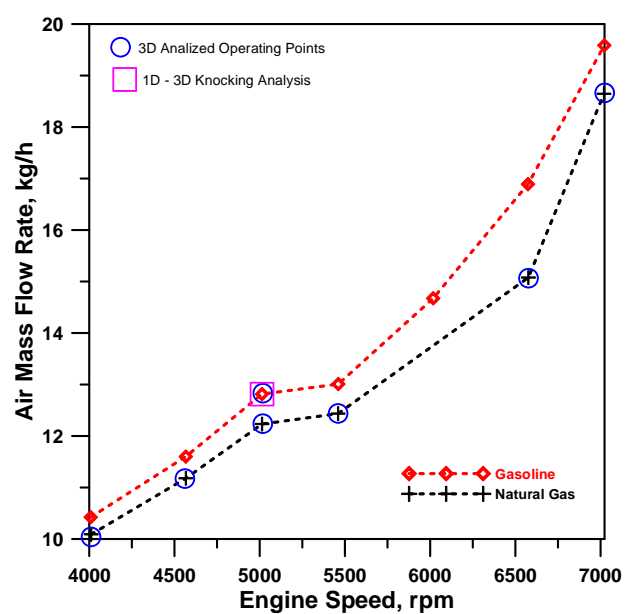

Fig. 2a Air Mass Flow Rate

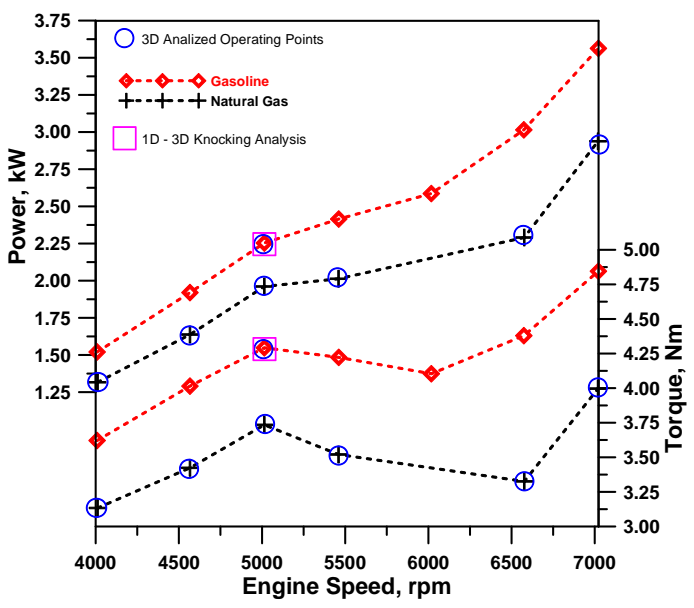

Fig. 2b Experimental Power and Torque

\section{Computational Methods}

\subsection{D Model - Whole Engine Analysis}

The 1D code employed in the simulations has been developed at the DIME over several years ${ }^{(8-12)}$. It is suitable for all main engine configurations and, in particular, is has been successfully applied during last years to the analysis of two-stroke engines $(8,11,12)$.

\subsubsection{Combustion Model}

The model, able to account for both engine geometrical and operating parameters (turbulence intensity, $\mathrm{A} / \mathrm{F}$ ratio, spark advance, load conditions and residual mass fraction), is based on a fractal description of the flame front area ${ }^{(13,14)}$. At first, turbulent eddies wrinkle the initial smooth flame surface of spherical shape, i. e. the laminar flame $A_{L}$. Then, the interaction between the turbulent flow field and the flame determines the development of a turbulent flame surface, $A_{T}$, which propagates at laminar flame speed $S_{L}$.

The turbulent flame area can be expressed in terms of the ratio of maximum and minimum wrinkling scales, $L_{\max }-L_{\min }$, and of the fractal dimension $D_{3}$, while the mass burning rate, $d m_{b} / d t$, is computed as a function of the flame front increase $A_{T} / A_{L}$ : 


$$
A_{T}=A_{L}\left(\frac{L_{\max }}{L_{\min }}\right)^{D_{3}-2}(1) ; \quad \frac{d m_{b}}{d t}=\rho_{u} A_{T} S_{L}
$$

The calculation of burning rate as expressed by equation (2), requires also the development of a geometrical model for the estimation of the laminar flame surface $A_{L}$ as well as the definition of a turbulence model for the estimation of the wrinkling scales, $L_{\min }-L_{\max }$, and fractal dimension $D_{3}$.

\subsubsection{Turbulence Model}

The wrinkling scales $L_{\min }-L_{\max }$ in equation (1), as well as the fractal dimension $D_{3}$, are computed as a function of the incylinder turbulent flow field using a two-equation $K-k$ approach, where $\mathrm{K}$ is the mean flow kinetic energy $\left(U_{f}\right)$ - whose production and destruction is mainly related to the intake and exhaust flow rates $\left(\dot{m}_{i n}\right.$ and $\left.\dot{m}_{e x}\right)-$ and $k$ is the turbulent kinetic energy, assumed isotropic. The turbulence intensity is finally derived from the $k$ definition and is used to compute $D_{3}$ and $l_{k}$. The turbulence model includes some tuning constants that have been identified through comparison with $3 \mathrm{D}$ derived mean turbulence data in a single operating condition, as reported in the result section of the paper.

\subsubsection{Scavenging Model}

The 1D model includes also a two-zone description of the scavenging process, ${ }^{(11,12)}$. The mass exchange phase is described as the superimposition of the mixing process between the burned and the unburned zone and the direct unburned mixture shortcircuiting through the exhaust port. At exhaust port opening, the burned gas zone present inside the cylinder exchanges mass with the exhaust pipe. When the intake port opens, a new unburned gas zone is initialized with the same thermodynamic properties and composition of the gas at the intake pipe end. This zone then grows over time and mixing with the burned gas zone begins. Later on, during scavenging, a direct short-circuiting flow of unburned mixture is considered. The model is capable of accurately computing the fraction of recirculated burned gas products. Their concentration considerably affects the laminar flame speed $S_{L}$ as well as the NO formation rate. All the relevant phenomena for engine performance and emissions, such as cylinder and port geometry, fluid-dynamics, burning rate, scavenging efficiency, etc., are physically linked in the proposed modeling approach, despite the limited modeling complexity and computing requirement.

\subsubsection{D Knock Model}

During the closed port period, the unburned gas zone (subscript $u$ ) can be considered as a homogeneous mixture of $N_{\text {spec }}$ chemical species, each one characterized by its own internal energy $e_{i}$ and mixture fraction $x_{i}$. The thermodynamic state of the unburned gas zone is identified by its temperature $T_{u}$, volume $V_{u}$, mass $m_{u}$, together with the overall cylinder pressure $p$. A rearrangement of the energy equation for this zone then leads to ${ }^{(15)}$ :

$$
\begin{aligned}
& \frac{d T_{u}}{d t}=\left(V_{u} \frac{d p}{d t}+\frac{d Q_{\text {chem }}}{d t}-\frac{d Q_{w}}{d t}\right) / m_{u} c_{p u} \\
& \frac{d Q_{c h e m}}{d t}=-m_{u} \sum_{i=1}^{N_{\text {spec }}} e_{i} \frac{d x_{i}}{d t}
\end{aligned}
$$

$c_{p u}$ being the constant pressure specific heat and $d Q_{w} / d t$ the heat transfer to the wall. The variation in composition $\left(d x_{i} / d t\right)$ of the $i$ - th specie in the eq. (4) is computed through the solution of a kinetic scheme in the unburned zone. Depending on instantaneous thermodynamic conditions, the latter term may be present or not. If present, a certain amount of heat, $d Q_{\text {chem }} / d t$, is consequently released, denoting the occurrence of auto-ignition phenomena.

Hence, two knock indicators can be defined:

$$
Q_{u b}=\int \frac{d Q_{c h e m}}{d t} d t \quad(5) ; \quad x_{Q u b}=\frac{Q_{u b}}{m_{f} L H V} * 100
$$

The first $\left(Q_{u b}\right)$ represents the total heat released in the unburned gases, while the second $\left(x_{Q u b}\right)$ is normalized with respect to the overall chemical heat available in the injected fuel. Results presented in the following refer to a reduced kinetic mechanism for the oxidation of iso-octane and n-hepthane mixtures developed by Tanaka and Keck ${ }^{(16)}$ including 5 elements, 32 species and 55 reactions for the gasoline operation, while the Gri-MECH is used for the CNG one.

\subsection{D Model}

\subsubsection{Computational Grid}

3D-CFD simulations are carried out using Star-CD, licensed by CD-Adapco. The computational domain covers the combustion chamber together with the port portions within the engine head. Only half of the engine is considered for symmetry reasons. Particular care is devoted to the grid generation, in order to minimize cell distortion and limit numerical instabilities arising from the presence of poor quality cells. The resulting grid, made up of 550000 cells at BDC and nearly 324000 cells at TDC, is reported in Figure 3 below.

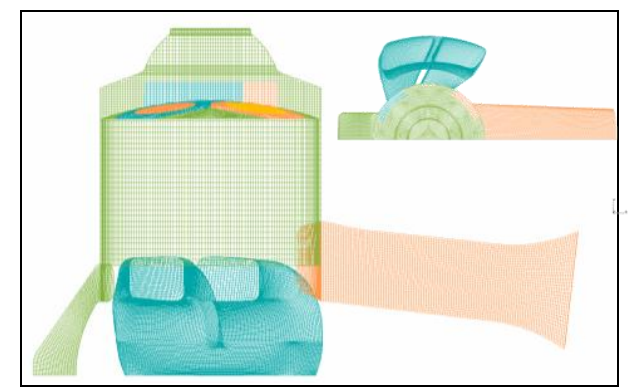

Fig. 3 Computational grid for the 3D calculations

\subsubsection{CFD Setup}

Every operation is modeled using multi-cycle analyses to assess the engine behavior in terms of flow field and scavenging. Each engine cycle covers a full $360^{\circ} \mathrm{CA}$ starting at $90^{\circ} \mathrm{CA}$ after Firing Top Dead Center (hereafter AFTDC), i.e. a few crank angle degrees before the exhaust port opening. Both initial and boundary conditions are derived from the above described 1D model of the engine. Particularly, time-dependent pressure and temperature traces are imposed at both the intake and exhaust ports in order to properly take into account ramming effects, which are well known to play a fundamental role in the scavenging performance. The initial gas composition is computed starting from the experimental measurements of exhaust gases. Only the species relevant for the adopted combustion model are used and, with reference to the cylinder and to the exhaust pipe, their mass fraction is derived assuming a complete combustion for the given Lambda. For the subsequent cycles, gas composition is 
directly mapped for each computational cell by means of a userdefined Fortran routine.

Concerning turbulence modeling, the realizable k- $\varepsilon$ model in its high-Reynolds formulation is chosen as a closure model. Heat transfer through the cylinder walls is accounted for by setting fixed temperatures on the different wall regions. Variable time steps are set ranging from $0.1{ }^{\circ} \mathrm{CA}$ during intake and compression down to $0.02{ }^{\circ} \mathrm{CA}$ during the early openings of the ports and during combustion. Finally, second-order accuracy is used for each of momentum, turbulence and energy equations.

\subsubsection{Combustion model - ECFM-3Z}

Among all the models available within the software, the ECFM$3 \mathrm{Z}$ model is chosen because of its ability to simultaneously account for both premixed combustion and auto-ignition due to knocking. The model takes into account the local sub-grid state of the gases, i.e. their composition and temperature, by applying a simple form of double conditioning (for each of mixing and reaction states) to the cell mean values solved by the transport equations in CFD simulations ${ }^{(17-19)}$.

\subsubsection{ECFM-3Z Knock Model}

The ECFM-3Z combustion model assigns the analysis of autoignition to a dedicated passive scalar, named YIG, which is transported by the local flow without any involvement in the combustion reactions. The model, described in ${ }^{(20)}$, is based on a correlation for the auto-ignition delay $\theta$ which has been fitted using the data specified in ${ }^{(21)}$. This correlation is a function of the local equivalence ratio, pressure, fresh gases temperature, EGR rate and octane number of the fuel. This delay is then integrated in time using the fictitious species YIG, which is initialized at zero:

$$
\frac{d Y I G}{d t}=Y T F \cdot f\left(\tau_{d}\right)
$$

$\tau_{d}=a \cdot(R O N / 100)^{b} \cdot\left(\frac{p}{1+Y_{\text {egr }}}\right)^{c} \cdot e^{\frac{g}{T_{u}}}$

where a, b, c, g are model constants YTF, Yegr and P are the local cell fuel fraction, residual gas fraction and pressure respectively and $T_{u}$ is the temperature of the unburned gases. Ignition is defined to be reached when YIG reaches the fuel tracer concentration, giving rise to the rapid development of a new local flame kernel.

As shown in ${ }^{(20)}$ this simple model accurately predicts the autoignition delay in typical engine conditions.

\subsubsection{Scavenging Coefficients}

In two-stroke engines the gas exchange process plays a key-role on both engine performance and emissions; at the same time, it represents one of the most critical process of the whole engine cycle. Therefore, an accurate representation of this process over a wide set of engine speeds and conditions is mandatory to assess the predictive capabilities of both 1D- and 3D- models. The validation process is primarily based on the comparison between numerical forecasts and experiments in terms of the following coefficients found in literature ${ }^{(22,23)}$ :

$$
\Lambda=\frac{\int \dot{m}_{f, i n} d t}{\rho_{a m b} \cdot V_{c}}
$$

\section{Charging efficiency (CE)}

$\eta_{c h}=\frac{\int \dot{m}_{f, i n} d t-\int \dot{m}_{f, e x} d t}{\rho_{a m b} \cdot V_{c}}$

\section{Retaining efficiency (RE)}

$\eta_{v}=\frac{\int \dot{m}_{f, i n} d t-\int \dot{m}_{f, e x} d t}{\int \dot{m}_{f, i n} d t}=\frac{\eta_{c h}}{\Lambda}$

where the subscript $f$,in indicates the fresh charge entering the cylinder through the transfer ports, the subscript f,ex indicates the fresh charge exiting out of the cylinder, the product $\left(\rho_{\mathrm{amb}} * \mathrm{~V}_{\mathrm{c}}\right)$ is a reference mass. Each integral is computed throughout the scavenging portion of the engine cycle, i.e. the crank angle range during which all the ports are simultaneously open. Concerning the numerical evaluation of the process, in the 3D simulations the above coefficients are computed by monitoring an additional scalar tracer representing the fresh charge entering and exiting the cylinder throughout the gas exchange process.

\section{Results}

\subsection{D Results - Scavenging and Combustion}

The 1D model of the whole engine is preliminarily validated against experiments in terms of both in-cylinder pressure traces and instantaneous pressure waves along the exhaust pipe. Figures 4 and 5 below show the in-cylinder and exhaust pressure traces for the gasoline- and CNG- fuelled revving speed of $5000 \mathrm{rpm}$ case respectively. As visible from the pictures, an excellent agreement between numerical forecasts and experimental evidence is observed for both gasoline and CNG. Comparable results are obtained over a wide range of engine speeds.

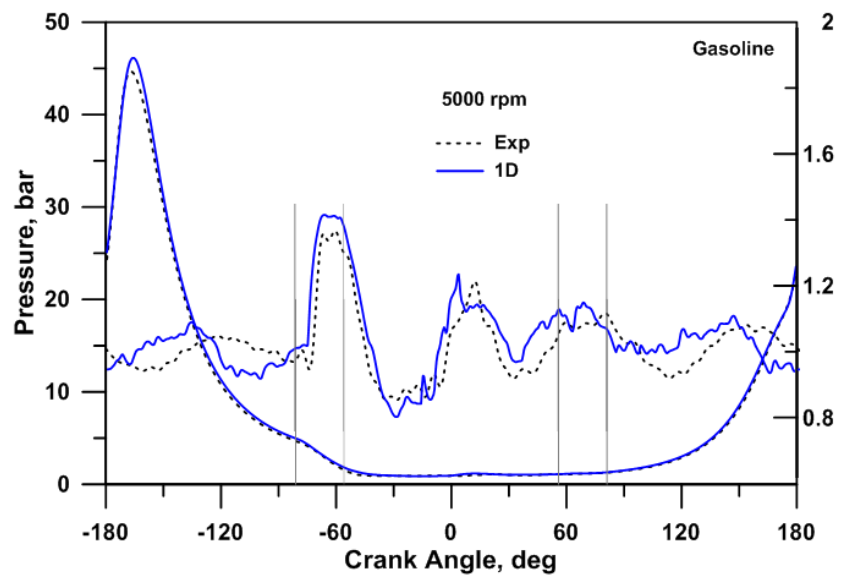

Fig. 4 In-cylinder and exhaust pressure - Gasoline, 5000 rpm

Delivery ratio (DR) 


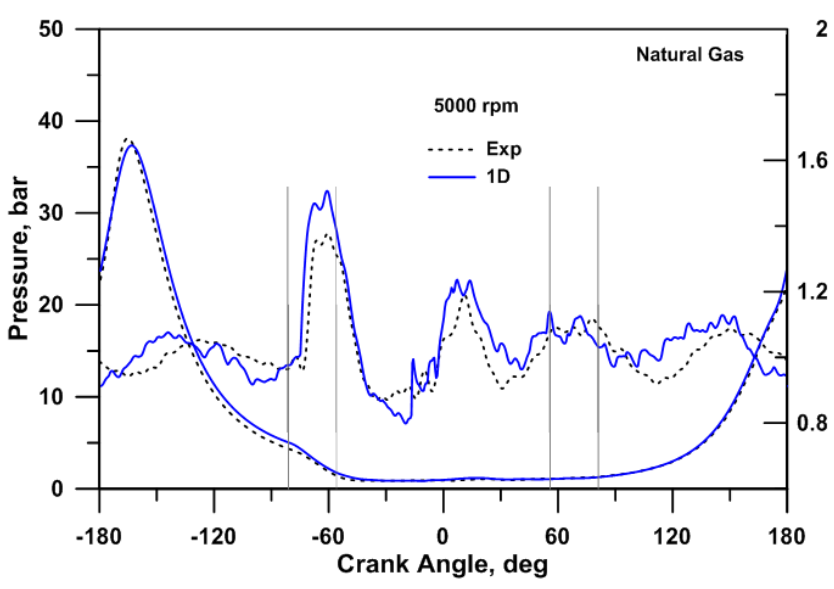

Fig. 5 Exhaust port pressure - CNG, $5000 \mathrm{rpm}$

\subsection{D Results - Scavenging and Combustion}

3D CFD investigations are carried out using time-dependent boundary conditions resulting from the validated 1D model; several cycles are analyzed to determine the minimum number to reach both a periodic engine condition and a stable scavenging behavior, i.e. the onset of constant scavenging coefficients.

At first, CNG fuelled conditions are modeled for three revving speeds (4000rpm @ $\lambda=1.025$; 5000rpm @ $\lambda=1.006$; 6500rpm @ $\lambda=0.892$ ) and for the same air to fuel ratio as the corresponding gasoline operations. A minimum of seven subsequent engine cycles are simulated in order to reach a satisfactory periodic convergence for each operation. The analysis of Figure 6 below shows relevant variations for the first three engine cycles, especially in terms of scavenging coefficients. The application of 1D- derived averaged pressure, temperature and velocities at each engine ports as initial conditions leads to a strong underestimation of the ramming effects, neglecting most of the complex three dimensional flow effects. Following cycle 4, variations are reduced, and the small perturbations between each engine cycle are now primarily due to slight tuning of the combustion model constants in order to better match the experimental pressure trace.

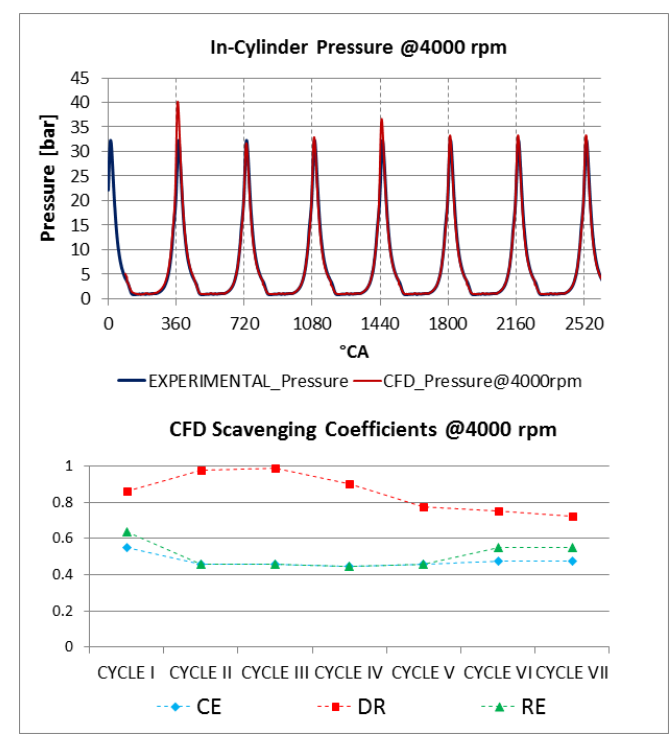

Fig. 6 In-Cylinder Pressure variation and Scavenging Coefficients - CNG, $4000 \mathrm{rpm}$
The above described numerical procedure allows the simulations to correctly capture both the scavenging behavior and the incylinder pressure history, with very limited variations of the spark advance and the same set of model constants.

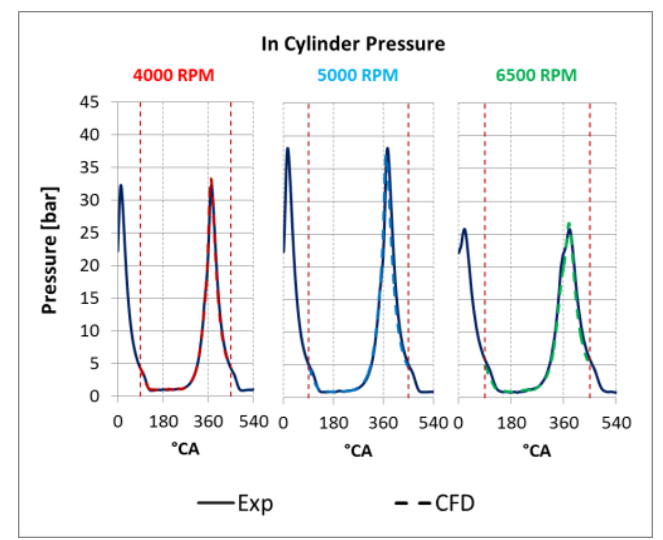

Fig. 7 CFD Pressure vs. experiments for different engine speeds
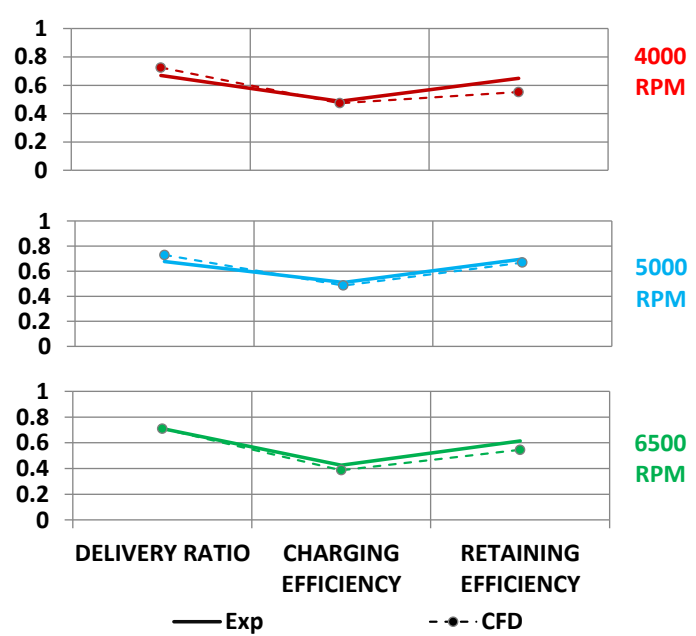

Fig. 8 CFD Scavenging Parameters vs. experiments for different engine speeds

Figures 7 and 8 above show the excellent agreement between CFD and experiments in terms of in-cylinder pressure and scavenging coefficients after 7 subsequent engine cycles and for different engine speeds. The use of 3D tools for the analysis of the full engine cycle allows the researchers to easily visualize the incylinder flow patterns and their evolution throughout the scavenging process. As an example, Figure 9 highlights the gasexchange operation for the CNG-fuelled case at $5000 \mathrm{rpm}$ engine speed. A view of the combustion chamber from the symmetry plane side is used to visualize the burned gas backflow towards the end of the exhaust stroke, as well as the presence or absence of a fresh charge short-circuit towards the exhaust port during the intake process.

As visible from the pictures below, a few degrees after the transfer port opening there is a relevant escape of fresh charge from the transfer port towards the exhaust, which is highlighted by the constantly increasing CNG concentration within the exhaust port. Due to the strong ramming effects, after a few further degrees (see 11d) a strong backflow from the exhaust pipe forces a relevant quantity of burned gases back into the cylinder, so that a non negligible internal EGR is present at port closure. 

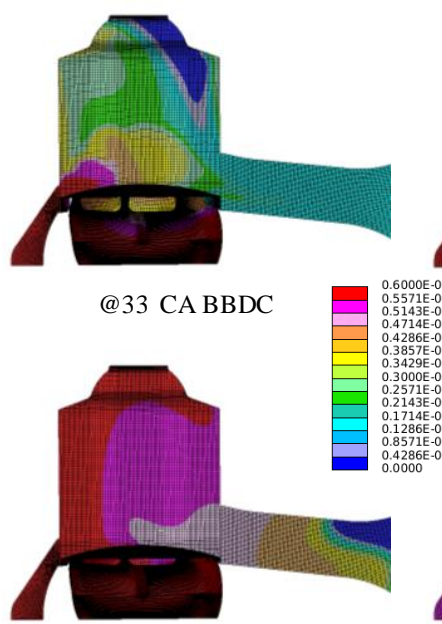

@15 CA ABDC

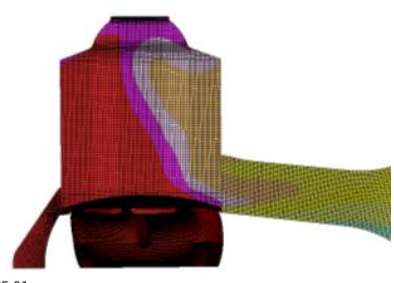

$@ 9$ CABBDC

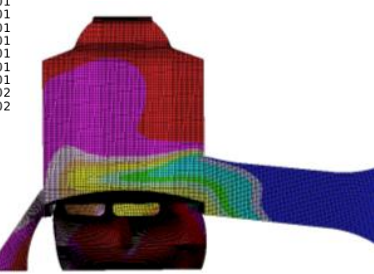

@31 CA ABDC

Fig. 9 Fuel concentration fields during the scavenging process $\mathrm{CNG}, 5000 \mathrm{rpm}$

Figure 10 below shows a sequence of pictures highlighting the combustion evolution for the CNG, $5000 \mathrm{rpm}$ case. The reaction progress variable is depicted, showing that, in view of the strong in-cylinder flow motion, a non-negligible percentage of the combustion chamber undergoes incomplete combustion. 3D CFD simulations are also used to extract some in-cylinder information, such as time-dependent in-cylinder average gas velocities, turbulence intensity and integral length scales, which are iteratively passed - for each tested condition - to the 1D model to better match the engine behavior, and particularly the combustion process.

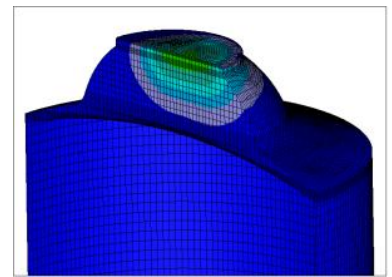

@ 8 CABFTDC

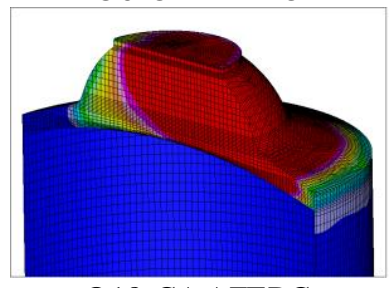

@ 18 CA AFTDC

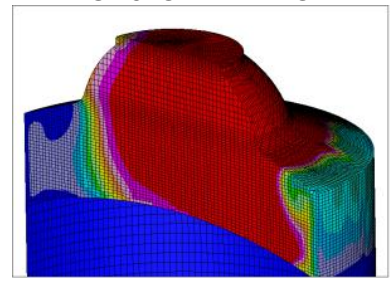

@68 CA AFTDC

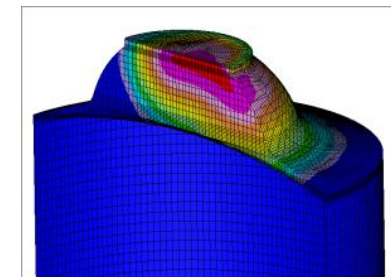

@2 CA AFTDC

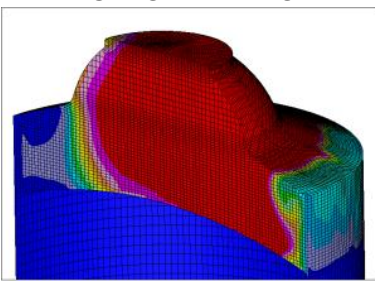

@ 48 CA AFTDC

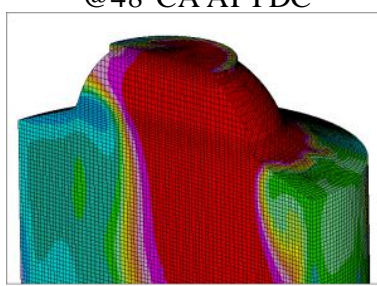

@ 88 CA AFTDC

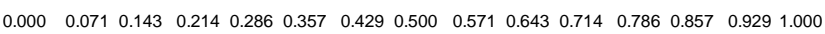

Fig. 10 Combustion model progress variable field during combustion - CNG, $5000 \mathrm{rpm}$

As an example, extracted data for the $4000 \mathrm{rpm}$ engine speed gasoline case are reported in Figure 11 below. The loop between

the two simulation tools in terms of boundary conditions, initial conditions and in-cylinder flow patterns is performed until differences in terms of key-parameter predictions are negligible.

As visible from Figure 11, in-cylinder average mean gas velocity and turbulent fluctuations show a very similar trend, reaching a peak level towards the end of the induction stroke then rapidly decaying during the compression. Turbulence decay is much faster than mean flow energy decay, reaching at almost null value a few degrees BFTDC.

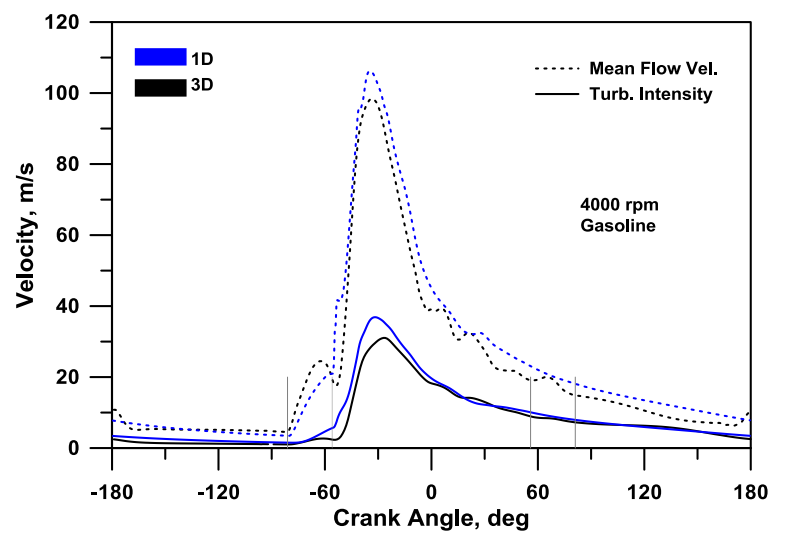

Fig. 11 In-cylinder average gas velocity and turbulence intensity

\subsection{Knock Limit}

\subsubsection{D Results}

Finally, a new set of 1D- and 3D- analyses is carried out aiming at finding the knock limit for the gasoline and CNG-fuelled engine.

Since for the CNG-fuelled operations no knock occurrence is verified during the experiments, the capability of the simplified 1D knock model to predict the occurrence of the phenomena is at first assessed modeling a gasoline operation which is experimentally - considered to be very close to knock. For the chosen engine condition (5000 rpm, spark advance $17{ }^{\circ} \mathrm{CA}$ BFTDC), knock is expected to occur only at the very late stages of the combustion process, when a limited unburned fuel fraction remains within the combustion chamber.

Figure 12 below shows the knock onset prediction for the gasoline $5000 \mathrm{rpm}$ operation. A limited auto-ignition appears towards the end of the combustion process, releasing an almost negligible portion of the total fuel chemical heat. This produces a limited increase of the unburned gas temperature with negligible effects on the in-cylinder pressure. At the end of the combustion process, a small fuel oxidation occurs, mainly in the low temperature reaction regime. Figure 13 below shows the effects of spark advance variations for the analyzed engine operation, confirming that a spark advance equal to $17^{\circ} \mathrm{CA}$ BFTDC can be considered as a knock-limit operation of the engine. The figure also shows that, for a light knocking operation, say 5-6\% of knock released heat, effects on in-cylinder pressure are almost undetectable by an experimental point of view. The same numerical procedure is then applied in order to assess the potentials of the conversion to the high-RON CNG fuel. The activity is at the very beginning, but some preliminary assessments emerge from the observation of Figure 14 below, where the knock investigation is reported for the $5000 \mathrm{rpm}$ operation adopting the knock-limited gasoline spark advance $\left(17^{\circ} \mathrm{CA} \mathrm{BFTDC}\right)$ for the two fuels. 


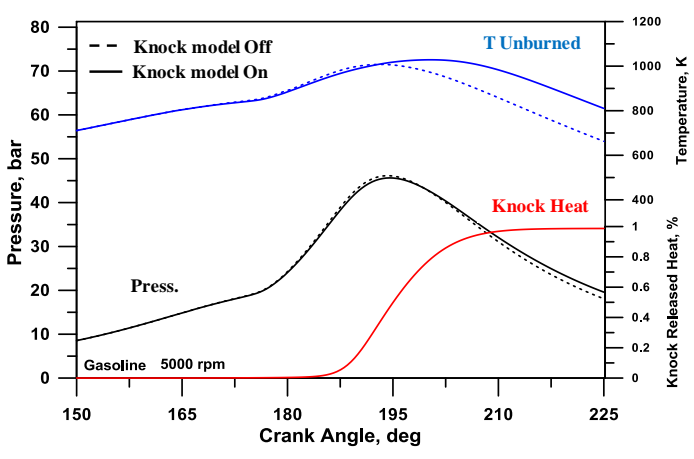

Fig. 12 In-cylinder conditions in a light-knocking operating point (5000 rpm, Gasoline, 1D model)

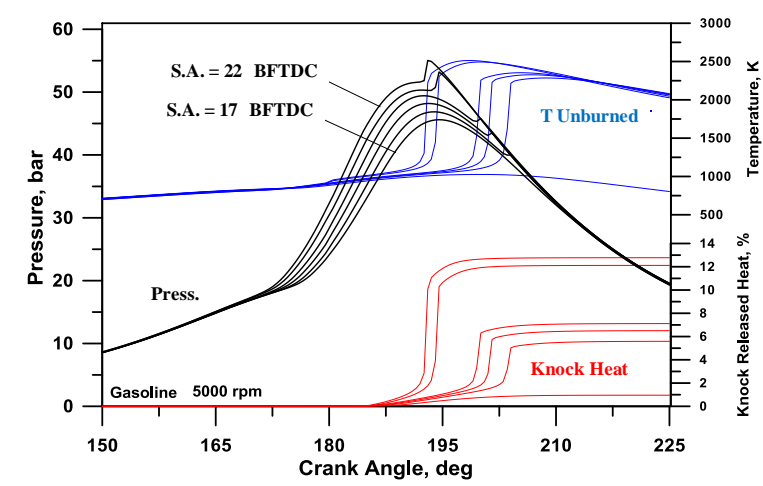

Fig. 13 Spark advance sweep effects on in-cylinder conditions (5000 rpm, Gasoline, 1D model)

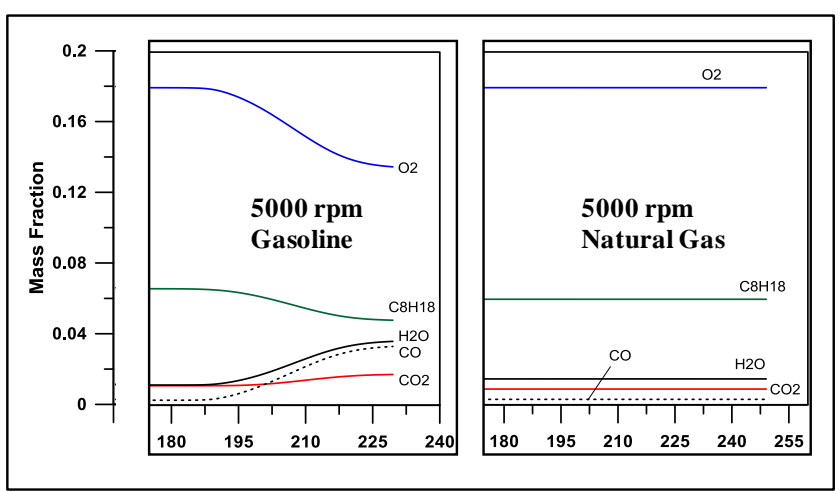

Fig. 14 Unburned gas composition in a knock-free operating point (5000 rpm, Gasoline vs. CNG, 1D model)

The analysis of Figure 14 clearly demonstrates that the conversion to CNG leads to a reduction in terms of knock probability, therefore allowing the engine to operate under more advanced spark timings and/or higher thermal loads.

\subsubsection{D Results}

The same numerical procedure already adopted for the CNGfuelled case (based once again on a multi-cycle analysis with subsequent mapping of the results onto the simplified model covering only the combustion chamber) is now carried out for the Gasoline-fuelled case. Figure 15 below shows the CFD incylinder pressure trace from the 3D simulations as well as information from a series of virtual sensors distributed inside the combustion chamber, used to investigate the supposed knock condition from a local perspective. The Spark Advance is slightly increased $\left(2{ }^{\circ} \mathrm{CA}\right)$ in order to evaluate its effects on the engine knock tendency. As visible from the picture, despite knock effects on the global in-cylinder pressure is almost negligible, highfrequency and relatively high-amplitude pressure fluctuations are experienced during the calculations at some combustion chamber's critical locations, such as sensor 1 . In order to quantitatively assess the knock intensity, MAPO, IMPO and DKI indices are computed and reported in Table 2 below. For the MAPO, IMPO and DKI definitions see ${ }^{(23)}$ for reference.

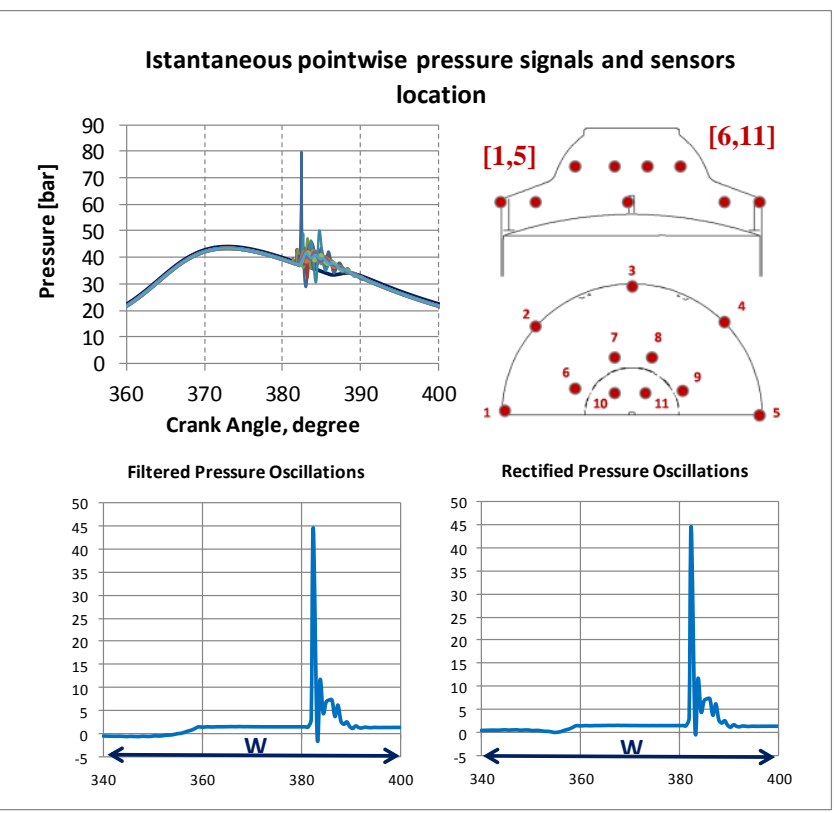

Fig. 15 CFD Knock-sensor locations and instantaneous point wise pressure signals - Gasoline, $5000 \mathrm{rpm}$

\begin{tabular}{|c|c|}
\multicolumn{2}{c}{ Table 2 Knock indices } \\
\hline & SA-2 $^{\circ} \mathbf{C A}$ \\
\hline MAPO & 44.5 \\
\hline IMPO & 7.4 \\
\hline DKI & $\mathbf{0 . 0 0 2 8}$ \\
\hline
\end{tabular}

The increase of the Spark Advance of $-2^{\circ} \mathrm{CA}$ leads to a DKI value of 0.0028 , far below the critical lower limit of 0.2 thus confirming that the reference spark value must be considered a limit value when taking into account cycle to cycle variability and the need for high engine life-cycle reliability. Once a reasonable prediction of knock occurrence is achieved, CFD analyses can be used to investigate the knock-limited potentials of the CNG fuelled engine. This last part of the activity, which is at a very early stage, aims at addressing possible engine modifications (either in terms of design or operative parameters) in order to at least equate, or even improve engine performance in comparison to the traditionally gasoline-fuelled one. Among the many possible parameters to be investigated, the initial choice falls on the modification of the engine compression ratio and/or of the spark advance. As expected, the knock limit of the standard CNG fuelled engine is much higher, in view of the higher octane index of the natural gas. Thus advanced spark timings can be used leading to higher in-cylinder pressures and partially recovering the drop of engine performance caused by the use of CNG. In addition, the combined use of higher compression ratios and more advanced spark timings leads to a further improvement of the overall engine performance, as well as to the increase of the engine fuel conversion efficiency, without approaching knockfavorable conditions: comparing data from Figure $2 b$ to those reported in Figure 16b below, it appears evidently that the 
improved knock resistance of CNG allows the engine to benefit from higher compression ratios and higher spark advances, eventually leading to a reverse performance trend.

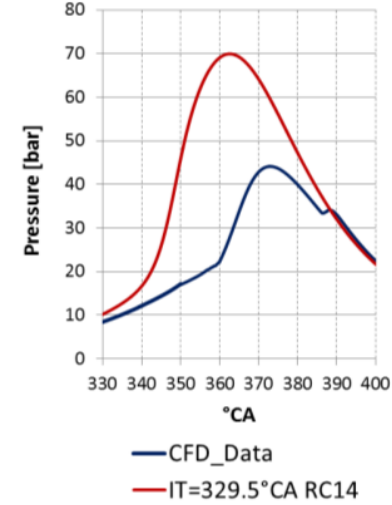

(a)

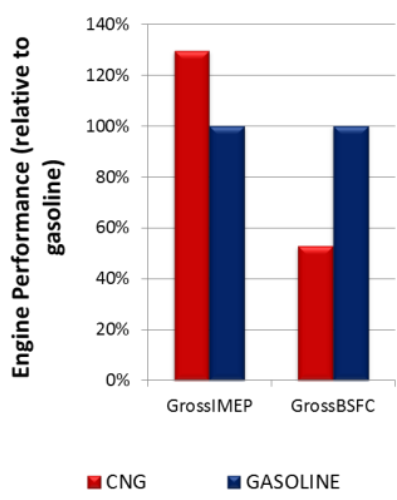

(b)
Fig. 16 (a) In-cylinder pressure traces - Gasoline vs MTBB/Rc CNG cases, 5000 rpm. (b) Gross IMEP and gross BSFC Gasoline vs. MTBB/Rc CNG cases, 5000 rpm

Among the CFD calculations still in progress, Figure 16(a) above shows the comparison between in-cylinder pressure traces for the original gasoline-fuelled engine and a high spark advance / high compression ratio (respectively fixed to $30.5^{\circ} \mathrm{CA}$ and 14) $\mathrm{CNG}$ fuelled engine for a revving speed equal to $5000 \mathrm{rpm}$. Engine performance is evaluated by means of the calculation of a gross Indicated Mean Effective Pressure (GrossIMEP) and a related gross Brake Specific Fuel Consumption (GrossBSFC) both evaluated over a cycle portion ranging from $40^{\circ} \mathrm{CA}$ BFTDC to $40^{\circ} \mathrm{CA}$ AFTDC. Results are listed in Figure 16(b) assuming values equal to $100 \%$ for the gasoline-fuelled case.

Despite the encouraging results shown below, particular care must be paid during the optimization process. Additional CFD calculations ${ }^{(24)}$ show in fact that an increase of the compression ratio might lead to knocking conditions when fueling the engine with relatively lean or excessively lean mixtures even for highly knock resistant $\mathrm{CNG}$.

\section{Summary and Conclusions}

The paper reports a combined numerical and experimental activity aiming at characterizing the behavior of a small displacement 2-stroke engine fuelled with Gasoline and CNG.

On the experimental side, a wide range of Gasoline and $\mathrm{CNG}$ engine operations are investigated. Measurements in terms of both engine performance and in-cylinder and port instantaneous pressure waves are performed. Experiments are also used to tune and validate the CFD models.

On the modeling side, both $1 \mathrm{D}$ and 3D tools are used to analyze both the scavenging process and the combustion over a wide range of operating conditions. Benefits from the interaction between the two modeling approaches are demonstrated and discussed, showing that the synergic use of different simulation tools allows the researchers to gain a better insight into the incylinder processes. Particular care is devoted to the modeling of the combustion process, in order to explore the knocking limits of the engine under both gasoline and CNG operations. The accuracy of both numerical approaches in predicting the onset of knocking is qualitatively confirmed by the experiments.

Finally, a preliminary assessment of potential benefits brought in by a combination of design and operating condition modifications for the CNG fuelled engine are investigated and briefly discussed.
Although this last activity is just at the beginning, the preliminary calculations show very promising results.

\section{REFERENCES}

(1) Conti L., Ferrera M., Garlaseo R., Volpi E., Cornetti, G.M. "Rationale of Dedicated Low Emitting CNG Cars", SAE Paper No. 932763

(2) Gimelli A., Grassia P., Migliaccio M.no, Unich A., "Sulla efficacia della regolamentazione del traffico dei veicoli con motori a c.i. nei centri urbani per il contenimento della produzione di inquinanti", International Congress Energy and Environmental, Capri, Italy, June 2002. (In Italian)

(3) Grechi D., Santino D., Monni F., Picini P., "Verso una mobilità pulita - emissioni inquinanti da veicoli a motore: dalla misure di concentrazione alle stime di impatto in area urbana", ACI, Firenze. (In Italian)

(4) Atkar, A. S., Tandan, V. J., Rairikar, S. D., Nair, C. K. J., Chaudhari, M. K. "Development Aspects of Conversion of 2stroke Gasoline Engine to Operate on Bi-fuel CNG and Dedicated CNG Mode", SAE Paper 962477

(5) Shanmugam, P., Anbukarasu, A. S., Babu, Y. R, Vinay Harne, Rairikar, S. D., Kavathekar, K. P., Thipse, S. S, Marathe, N., "Development of a 2-Stroke CNG Engine for 3Wheeler Vehicle for the Indian Market", SAE Paper 200926-0022

(6) Fontanesi, S, Gagliardi, V., Malaguti, S., and Mattarelli, E.," Multidimensional Cycle Analysis of a Novel 2-Stroke HSDI Diesel Engines", SAE Paper 2007-01-0161. 2007

(7) Lavy, J., Angelberger, C. Guibert, P., Mokhtari, S., "Towards a Better Understanding of Controlled Auto-Ignition (CAI $\left.{ }^{\mathrm{TM}}\right)$ Combustion Process From 2-Stroke Engine Results Analyses", SAE Paper 2001-01-1859

(8) Bozza F., Tuccillo R., de Falco D., "A Two-Stroke Engine Model Based on Advanced Simulation of Fundamental Processes", SAE paper 952139, SAE Int. Congr. \& Exp., Milwaukee, WI, sett. 1995,

(9) Bozza F., Gimelli A., Senatore A., Caraceni A., "A Theoretical Comparison of Various VVA Systems for Performance and Emission Improvements of SI Engines", SAE Paper 2001-01-0671, 2001

(10) Bozza F., Gimelli A., Tuccillo R., "The Control of a VVA Equipped SI-Engine Operation by Means of 1D Simulation and Mathematical Optimization", SAE Paper 2002-01-1107, SAE Trans. Vol. 111, 2002

(11) Bozza F. Gimelli A., "A Comprehensive 1D Model for the Simulation of a Small-Size Two-Stroke Engine", SAE Paper 2004-01-0999, also in "Modeling of Spark-Ignition Engines", SAE SP-1830, ISBN 0-7680-1366-6, pp. 165-177, e su SAE 2004 Transactions, Journal of Engines - section 3, vol. 113-3, pp. 758-770, ISBN 0-7680-1552-9, Luglio 2005.

(12) Bozza F., Gimelli A., Andreassi L., Rocco V., Scarcelli R., "1D-3D Analysis of the Scavenging and Combustion Process in a Gasoline and Natural-Gas Fuelled Two-Stroke Engine", SAE Paper 2008-01-1087, also in "Modeling of SI and Diesel Engines, 2008", pagg. 297-309, SAE SP-2156, ISBN 978-0-7680-1998-8.

(13) Matthews R.D., and Chin Y.W., "A Fractal-Based SI Engine Model: Comparisons of Predictions with Experimental Data," SAE Paper 910075, 1991.

(14) Yoshiyama S., Tomita E., Zhang Z., Hamamoto Y., "Measurements and Simulation of Turbulent Flame Propagation in a Spark Ignition Engine by Using Fractal Burning Model”, SAE Paper 2001-01-3603, SAE Trans. Vol. 110, 2001. 
(15) Bozza F., Fontana G., Galloni E., Torella E., “3D-1D Analyses of the Turbulent Flow Field, Burning Speed and Knock Occurrence in a Turbocharged SI Engine", SAE 2007 Transaction, Journal of Engines - section 3, vol. 116, pp. 1495-1507, ISBN 978-0-7680-1982-7, 2008.

(16) Tanaka S., Ayala F., Keck J., "A Reduced Chemical Kinetic Model for HCCI Combustion of Primary Reference Fuels", Combustion \& Flame, 132, pp. 219-239, 2003.

(17) Duclos, J.M., Zolver, M., and Baritaud T. 1999. '3D modeling of combustion for DI-SI engines', Oil \& Gas Science and Technology - Rev.IFP, 54(2), pp. 259-264.

(18) Colin, O. and A. Benkenida "The 3-Zones Extended Coherent Flame Model (ECFM3Z) for Computing Premixed/Diffusion Combustion" Oil \& Gas Science and Technology - Rev. IFP, Vol. 59 (2004), No. 6, pp. 593-609

(19) Colin, O., Pires da Cruz, A. and Jay, S. 2004. 'Detailed chemistry bases auto-ignition model including low temperature phenomena applied to 3D engine calculations', 30th Symposium on Combustion, The Combustion Institute

(20) Lafossas, F.A., Castagne, M., Dumas, J.P. and Henriot, S. "Development and Validation of a Knock Model in Spark Ignition Engines Using a CFD code", SAE Paper 2002-012701

(21) Guibet, J.C. “ Les essences. In Carburants et Moteurs”, Éditions Technip (2nd ed.), 1997, Paris.

(22) Blair, G.P., "Design and Simulation of Two-Stroke Engines", SAE, Warrendale, PA, 1996

(23) Heywood, J.B. and Sher, E., "The Two-Stroke Cycle Engine", SAE, Warrendale, PA, 1999.

(24) Bozza F., Fontanesi S., Gimelli A., Severi E., Siano D., "Numerical and Experimental Investigation of Fuel, Effects on Knock Occurrence and Combustion Noise in a 2-Stroke Engine," SAE Paper 2012-01-0827, also in SAE Int. J. Fuels Lubr. 5(2):2012, doi:10.4271/2012-01-0827

\section{ACRONYMS AND ABBREVIATIONS}

$\begin{array}{ll}\text { A(F)BDC } & \text { After (Firing) Bottom Dead Center } \\ \text { B(F)BDC } & \text { Before (Firing) Bottom Dead Center } \\ \text { BSFC } & \text { Brake Specific Fuel Consumption } \\ \text { DC } & \text { Direct Current } \\ \text { DKI } & \text { Dimensionless Knock Indicator } \\ \text { FTDC } & \text { Firing Top Dead Center } \\ \text { IMEP } & \text { Indicated Mean Effective Pressure } \\ \text { IMPO } & \text { Integral of Modulus of Pressure Oscillation } \\ \text { LHV } & \text { Lower Heating Value } \\ \text { MAPO } & \text { Maximum Amplitude of Pressure Oscillation } \\ \text { RC } & \text { Compression Ratio } \\ \text { RON } & \text { Research Octane Number } \\ \text { SA } & \text { Spark Advance } \\ \text { SI } & \text { Spark Ignition } \\ \text { WOT } & \text { Wide Open Throttle }\end{array}$

\section{NOMENCLATURE}

\section{Latin}

$\begin{array}{ll}A_{L} & \text { Laminar Flame Surface } \\ A_{T} & \text { Turbulent Flame Surface } \\ C_{p} & \text { Pressure loss Coefficient } \\ C_{p u} & \text { Unburned Gas Specific Heat at Constant Pressure } \\ D_{3} & \text { Fractal dimension } \\ e_{i} & \text { Internal Energy of the } i \text {-th specie } \\ E & \text { Total Energy per unit mass } \\ \text { F } & \text { Flux Term } \\ \text { f } & \text { Friction Coefficient }\end{array}$

$S_{L}$

$T_{u}$

$u^{\prime}$

$V_{c}$

$V_{u}$ $x_{f}, Y T F$

$x_{i}$ $x_{r}, Y e g r$

$x_{Q u b}$

YIG

$f_{\text {, }}$.

$f_{\text {, }}$,

\section{Greeks}

$\eta_{c h}$

$\eta_{v}$

$\lambda$

$\Lambda$

$\rho$

$\rho_{\mathrm{u}}$

$\rho_{\mathrm{amb}}$

$\Omega$
Total Enthalpy per unit mass

Kinetic Energy of Turbulent Flow Field

Kinetic Energy of the mean Flow Field

Lower Heating Value

Maximum turbulent length scale

Minimum turbulent length scale

Burned gas mass

Fuel Mass

Unburned gas mass

Total Mass trapped in the Cylinder

Fresh Charge trapped in the Cylinder

Mass Flow Rate

Exhaust Mass Flow Rate

Intake Mass Flow Rate

Total Number of the $i$-th species

Pressure

Rate of heat exchange

Chemical Reaction Heat

Total Heat released in the Unburned Gases

Wall Exchange Heat

Source Term

Laminar Flame Speed

Unburned Gas Zone Temperature

Mean Flow Field velocity

Turbulence intensity velocity

Engine Displacement

Unburned Gas Volume

Fuel fraction

Composition of the $i$-th specie

Residual gas fraction

Normalized Heat released in the Unburned Gases

3D Knock Parameter

Fresh Charge to the Cylinder

Fresh Charge exiting out of the Cylinder

\section{Charging Efficiency}

Retaining Efficiency

Air Index

Delivery Ratio

Gas Density

Unburned Gas Density

Ambient Air Density

Duct area 